\title{
Using the arts: Learning from a community consultation on health and wellbeing
}

\begin{abstract}
Local service commissioners require information about a community's needs in order to make spending decisions with limited funds. Gaining the knowledge required can be problematic. This paper presents the findings from an innovative project which harnessed the arts in order to facilitate expression of a community's health and wellbeing needs. The project in the form of an arts-based community consultation, was developed in partnership by a range of agencies and organisations engaged with a particular community. A qualitative evaluation study was devised to capture the process of delivering the community consultation. The findings demonstrated that an effectively managed arts-based creative consultation process, can be a powerful mechanism for establishing a community's perspective on their health and wellbeing.
\end{abstract}

\section{Key points}

Arts-based activities can be an effective vehicle to generate community consultation.

Facilitating a community to offer their views can provide commissioners of health and social care services greater insight into local needs.

Arts-based activities can not only provide insight but offer added value in terms of strengthening both the community's identity and resilience. 


\section{Introduction}

Local service commissioners require information about a community's needs in order to make spending decisions with limited funds. Traditionally, decisions have been made based upon available written data such as population information and other records of service takeup. One commissioning partnership sought to explore an alternative approach that could offer richer insights to need and enhance local dialogue.

\section{Background to the study}

Historically the arts have been associated with health and wellbeing interventions first within clinical settings then later within communities (Putland, 2008). A literature search indicated that there was a dearth concerning the use of the arts to facilitate community consultation. This paper presents findings from a community project where the arts were used to explore the health and wellbeing needs of a community and offers an initial exploration of the potential opportunities offered by this approach.

A Partnership of agencies drawn from health, social care and local authorities as well as charities came together with a shared purpose. All were keen to use a new approach to consultation, using the arts. To achieve their aim the Partnership decided to ask the young people from the community to produce a film about what health and wellbeing meant within their community. Together the Partnership and some of the young people recruited a film making company to facilitate the project. The film-makers had experience of both community projects and working with young people. When the film had been produced it was screened at a community event attended by residents, the filmmakers, health and social care professionals 
and service commissioners. The Partnership aimed to leave a legacy from the consultation process which was the opportunity for local young people to learn new skills related to film production. They also required evaluation of their new initiative in particular the process of devising a creative consultation process and also evidence of its effectiveness.

\section{Methodology}

The evaluation adopted a qualitative approach. Data collection methods included participant observation and semi-structured interviews. Ethical approval for the study was gained through the team's University Research Ethics Committee.

During the film making a member of the research team joined the young people as they developed their film and observed the various stages of production. Further observations were made by the Research Team at the community event when the young people presented their film to their community and local service commissioners.

Following the film's screening semi-structured interviews were conducted with key members of the Partnership and the artists who had supported the young people. In addition a focus group was held with the young people to discuss their experiences. All interviews were audio recorded and transcribed for thematic analysis.

\section{Findings}

Key categories emerged from the thematic analysis related to:

- Delivery of the project 
- Practical/Planning issues

- Factors that encourage community engagement

These main themes and constituent subthemes are presented in table 1 and elaborated on below.

\begin{tabular}{|c|c|}
\hline Main themes & Sub themes \\
\hline Delivery of the project & $\begin{array}{l}\text { - A shared understanding of purpose. } \\
\text { - The building and maintaining of relationships. } \\
\text { - Understanding of roles and responsibilities. }\end{array}$ \\
\hline Practical/Planning issues & $\begin{array}{l}\text { - Project timings } \\
\text { - Selection of an appropriate arts intervention. } \\
\text { - Selection of a suitable venue or location of the } \\
\text { intervention. } \\
\text { - Peer attitudes to participation. }\end{array}$ \\
\hline $\begin{array}{l}\text { Factors that encourage } \\
\text { community engagement }\end{array}$ & $\begin{array}{l}\text { - } \text { Encouraging ownership } \\
\text { - Working with a trusted individual } \\
\text { - Selection of artists }\end{array}$ \\
\hline
\end{tabular}

Table 1: Summary of key themes emerging from the data

\section{Theme One: Delivery}

Shared understanding of purpose

A shared purpose and language existed within the Partnership and was conducive to its success in delivering the project. The data suggested this arose because many of the members had either worked together before or had inherently similar approaches to working with the community. However, despite a shared language among the Partners the data indicated that 
terminology used by its members (for example 'wellbeing') was not always understood in the same way by the community. Thus at times the message of the project was not fully communicated to everyone. Furthermore, professionals being interviewed within the film used technical terminology not fully understood by the young people who could then struggle to compose follow up questions spontaneously.

\section{Building and maintaining relationships}

Evidence within the data showed effective relationships are crucial to this type of project and generally time is need to consolidate such working relationships. The Partnership benefitted from a network of existing working relationships enabling it to function more quickly as a cohesive unit. However, time constraints potentially restricted the relationship that the partnership could build with residents and may have limited the community's ownership of the project.

\section{Understanding of roles and responsibilities}

Due to the pre-existing relationships, roles and responsibilities appeared to have been assumed and subconsciously allocated. For example, the Partnership members formed two distinctive groups; one strategic and the other engaging with the practicalities of delivery. Although largely an effective arrangement there were limitations including those with shorter working relationships feeling uncertain about what was happening and their contributions. However the shared sense of responsibility within the Partnership helped it to overcome the minor issues that arose, keeping the project on track.

\section{Theme two: Practical/planning issues}

Project timings 
Time was a limitation recognised by all, affecting all aspects of the project from relationship building to the ability to recruit the target number of young people, the production of the film and its screening at short notice. However, the time-related issues were overcome by there being a key person with a strong pre-existing relationship within the community who 'brokered' the project with the residents.

\section{Selection of an appropriate arts intervention}

Data showed thorough consideration of the most engaging type of intervention for the community. Those who participated found the choice made to be a good one. However it is noteworthy that responses were from young people who completed the project and not those who dropped out. A limitation for the project was the choice of film topic. Some members of the Partnership and the young people highlighted that 'wellbeing' had been a difficult concept for the community to understand suggesting a need for a shared definition of wellbeing early in project planning.

\section{Selection of a suitable venue or location of the intervention}

The selected venue (the youth club on the community's estate) meant the young people felt at ease joining the project. Furthermore, the venue being within the community was convenient for the adult residents to attend the film screening. Another key factor related to the venue was its association with one member of the Partnership who had an existing strong, well established relationship with the community.

\section{Peer attitudes to participation}

Findings showed that the perceptions of peers can be a key influence on participation. As noted by Hampshire and Matthijsse (2010) even if a project is well planned the negative 
perceptions of peers can limit recruitment and therefore undermine the value of the intervention. The findings of this study suggest that peers will challenge participants even after completion of an intervention. In this case the perceptions of peers was only known once the film was in the public domain and so it cannot be gauged how peers' views influenced counterparts' decisions to make the film. This raises questions about how projects counter and manage peer comments given their potential to undermine the value of a project to young participants and individuals' self-esteem - an issue of particular importance given the purpose of many arts based projects is to build self-esteem. The implication is that strategies employed to support young people must cover their recruitment, participation and also the immediate post intervention period. This is particularly relevant if the project produces something that is publically accessible. In the context of this project the young people were resilient and defended their film to their peers which could be a reflection of their pride in their work and sense of ownership of the project.

\section{Theme three: Factors that encourage community engagement}

\section{Encouraging ownership}

Project ownership was encouraged from the start by including the young people in recruiting the artists. The young people quickly identified people they would not wish to work with and their presence helped the Partnership identify less appropriate candidates for example Partners noted an interviewee's negative body language projected towards the young people.

\section{Working with a trusted individual}

The engagement of the young people was strongly influenced in the early stages by a member of the Partnership's delivery team because they had a strong pre-existing relationship with the community particularly the young people. The relationship was vital given project timescales 
because the individual concerned could engage the young people and introduced them to the artists who were from outside the community. Despite this there were still some difficulties apparent in recruiting and retaining young people on the project.

\section{Selection of artists}

The outcomes of this project were enhanced by the artists having previous experience of working with young people in other communities. The value of experienced artists is highlighted within the literature as is the need for them to be knowledgeable about community development processes (Cameron et al. 2013).

The evidence from this study also suggests that the artists being 'outsiders' was beneficial in terms of not restricting them or the young people in how they developed the film. Of course this finding has to be viewed in context and as highlighted the artists had a very positive introduction into the community so how effective unsupported 'outsiders' might be in another setting is difficult to gauge.

Finally, another factor that enhanced the experience for the young people was the availability of the artists' previous work on social media. This was instrumental to the young people establishing the artists' credibility as professionals.

\section{Added value of the project}

In addition to the findings presented above the data revealed added value resulting from the project. For example the resulting film not only informed commissioners about local needs but also acted as a catalyst for the community to have a more open and frank discussion of specific health and wellbeing concerns with the commissioners attending the film screening. 
A key finding concerning added value was that for the young people producing the film had gone beyond a feeling of pride in the film as the experience had resulted in lasting change on their lives. Stickley and Eade (2013) highlight how interventions aimed at mental health patients had provided a legacy in terms of encouraging people to access 'new worlds'. In a similar way the young people involved in this project stated that they were now motivated to try new things that they would not have previously believed themselves capable of. Improved self-esteem and increased motivation have also been highlighted as outcomes in other studies (Hacking et al. 2006 and Wood et al. 2011).

Interview data revealed insight into how participating in the project had wider benefits for the both the young people and the community. The artists believed that the film-making process which brought young people and adults from the community together had started to 'break down barriers'. The young people themselves identified that their views of the adults had altered as they had not expected so many positive viewpoints about the area. The young people also valued the opportunity to know more about the changes to their community over time and to hear what life had been like in the past. Collectively these factors seemed to have generated within the young people a greater attachment to their community and to some a degree pride in their area. Therefore, a key benefit of the film was its role in enabling the community to reflect on their context and its history and to draw the attention of professionals to their concerns and priorities for attention. Research data indicated that the opportunity to view the film with in a relaxed environment had been instrumental to encouraging community members to openly express discuss their true needs. 


\section{Discussion}

The three key themes emerging from the data: delivery of the project, practical/planning issues and factors that engage, will be discussed within the context of the general literature related the use of the arts in health care and guidance suggested for those electing to use this innovative approach to consult the public in the future.

\section{Delivery of the project}

This study highlighted the importance of developing common understanding and definition of concepts from the outset of a project and revisiting understandings throughout the life of the work to ensure effective communication. Similarly, South (2006) has identified that a shared language between all who engage with a project is important for success. Echoing the literature, study findings also showed that effective relationships are crucial to the development of projects within the community (Jones et al.2013).

\section{Practical/planning issues}

The findings of this study indicated that it would have been beneficial to have had more time for the work but some specific factors unique to the project helped to overcome time constraints. Hence when planning such an intervention it would be advisable to embrace these findings and those of the literature which indicate that projects need sufficient time to embed into the community (Cameron et al. 2013 and South, 2006).

Another important planning issue that our findings highlighted was the choice of venue for the screening of the film. In this study the youth club was a familiar place at the hub of the 
local community and it exhibited the engaging factors discussed in the literature for example being comfortable, accessible and welcoming (Cameron et al, 2013).

A further finding was that the selection of an appropriate arts intervention is a key issue related to success and reflects the literature which stresses the need to match the type of intervention to the community/participants' interests (Cameron et al. 2013 and South, 2006). However, even with the selection of an appropriate intervention not all available project places were taken up by local young people. This could have reflected a lack of time for recruitment to the project but equally a lack of their interest. The lower take up by the young people may also relate to peer perception for example there is discussion in the literature of how an intervention perceived by other young people as 'uncool' could influence participation and retention (Hampshire and Matthijsse 2010). The findings of this study identified the need to plan for this at various points in the life-time of the project and that the level of ownership the young people feel is a protective factor against attrition.

\section{Factors that encourage community engagement}

The selection of artists was identified as an important factor in engaging the young people with the project and supports findings in the literature which highlight that the professionalism of the facilitator/project leader is crucial (South, 2006) as is ensuring the facilitator's role meets the expectations of participants (Hampshire \& Matthijsse, 2010). Equally facilitators of interventions should be experienced in community development as well as their arts ability. The literature has also highlighted the need for opportunities that allow for shared leadership of activities between project facilitator and community participants (South \& Philips, 2014) and the findings from this study concurred with this perspective. As the literature notes it is important for any community engaging with an arts 
intervention to have a social/health/voluntary infrastructure in place to ensure people who choose to change have the opportunity to do so at the point of readiness. This was relevant in this project and an aspect which the Partnership came to appreciate and acknowledge as the project progressed. Despite a lack of planning for such provision at the outset, the Partnership was committed and acknowledged their responsibility to put such support in place in the future.

\section{Limitations of the study}

This was a qualitative study designed to capture the process of delivering an arts-based community consultation. However, there were limitations to the findings due to the project being of fixed duration and only being delivered within one specific community. This reduces the generalizability of the findings but this preliminary exploration suggests that if managed effectively such methods of engagement can be a powerful mechanism for establishing a community's perspective on their health and wellbeing. On the basis of these initial findings an evaluation of an arts project of longer duration with several different communities would provide better knowledge of the long-term impact of using the arts to promote health.

\section{Conclusion}

Findings from this study indicate that an arts-based creative consultation can be highly effective. However, the study has also indicated that there are certain provisos to utilising this new and innovate method of consultation. We have found that it is important to begin with the community being facilitated to produce an arts-based artefact. But it is essential for this to be combined with a subsequent, informal community event for sharing the artwork in a 
comfortable familiar place. Then, the artwork becomes the trigger for in-depth, and at times very personal discussion which reveals to professionals commissioning and providing services the community's perspectives about their health and wellbeing experience in their own locality.

\section{Ethical Approval}

All research procedures have been performed in compliance with relevant laws and institutional guidelines and the study received University ethical approval.

\section{Conflict of Interest}

There are no conflicts of interest to declare.

\section{References}

Cameron M, Crane N, Ings R, Taylor K (2013) Promoting well-being through creativity: how arts and public health can learn from each other. Perspectives in Public Health 133: $52-59$.

Hacking S, Secker S, Kent L (2006) Mental health and arts participation: the state of the art in England. Journal of the Royal Society of Health Promotion 126: 121-127.

Hampshire K, Matthijsee, M (2010) Can arts projects improve young people's wellbeing? A social capital approach. Social Science and Medicine 71: 708-716. 
Jones M, Kimberlee R, Deave T, Evans S (2013) The role of community centre-based arts, leisure and social activities in promoting adult wellbeing and healthy lifestyles. International Journal of Environmental Research and Public Health (10): 1948-1962.

Putland C (2008) Lost in translation: the question of evidence linking community-based arts and health promotion. Journal of Health Psychology 13: 265-276.

South J, Phillips G (2014) Evaluating community engagement as part of the public health system. Journal of Epidemiology and Community Health (68): 692-696.

South J (2006) Community arts for health: an evaluation of a district programme. Health Education 106 (2): 155-168.

Stickley T, Eades M (2013) Arts on prescription: a qualitative outcomes study. Public Health, 127:727-734.

Wood M, Molassiotis A, Payne S (2011) What evidence is there for the use of art therapy in the management of symtoms in adults with cancer?: A systematic review. Psycho-oncology 20: $135-145$. 